\title{
THE OCEAN OBSERVING SYSTEM FOR TROPICAL CYCLONE INTENSIFICATION FORECASTS AND STUDIES
}

Gustavo Goni $^{(1)}$, Mark DeMaria ${ }^{(2)}$, John Knaff ${ }^{(2)}$, Charles Sampson ${ }^{(3)}$, James Price ${ }^{(4)}$, Avichal Mehra(5),

Isaac Ginis $^{(6)}$, I-I Lin ${ }^{(7)}$, Paul Sandery ${ }^{(8)}$, Silvana Ramos-Buarque ${ }^{(9)}$, M. M. Ali ${ }^{(10)}$, Francis Bringas ${ }^{(11)}$, Sim Aberson ${ }^{(1)}$, Rick Lumpkin ${ }^{(1)}$, George Halliwell ${ }^{(1)}$, Chris Lauer ${ }^{(12)}$, Eric Chassignet ${ }^{(13)}$, Alberto Mavume ${ }^{(14)}$, K. Kang ${ }^{(15)}$

${ }^{(1)}$ NOAA (National Oceanic and Atmospheric Administration) Atlantic Oceanographic and Meteorological Laboratory, 4301 Rickenbacker Causeway, Miami, FL 33149, USA, Email: Gustavo.Goni@noaa.gov, Sim.Aberson@noaa.gov, Rick.Lumpkin@noaa.gov, George.Halliwell@noaa.gov

(2) NOAA (National Oceanic and Atmospheric Administration) Regional and Mesoscale Meteorology Branch, Fort Collins, CO, USA, Mark.DeMaria@noaa.gov, Knaff@cira.colostate.edu

(3) Naval Research Laboratory, Monterey, CA 93943, USA, sampson@nrlmry.navy.mil

(4) Woods Hole Oceanographic Institution, 266 Woods Hole Road, Woods Hole, MA 02543, USA, jprice@whoi.edu

${ }^{(5)}$ NOAA (National Oceanic and Atmospheric Administration) National Centers for Environmental Prediction, 5200 Auth Road, Camp Springs, Maryland 20746 USA, Email: Avichal.Mehra@noaa.gov

${ }^{(6)}$ University of Rhode Island, Graduate School of Oceanography, South Ferry Rd., Narragansett, RI O2882 USA, Email: iginis@gso.uri.edu

(7) Department of Atmospheric Sciences, National Taiwan University, No. 1, Sec. 4, Roosevelt Road, Taipei, 10617 Taiwan (R.O.C.), Email: iilin@as.ntu.edu.tw

${ }^{(8)}$ Center for Australian Weather and Climate Research, Melbourne, GPO Box 1289, Melbourne, VIC 3001, Australia, Email:P.Sandery@bom.gov.au

${ }^{(9)}$ Mercator Ocean, Ramonville St. Agne, 8-10 rue Hermès, 31520 Ramonville St. Agne, France, Email: silvana.buarque@mercator-ocean.fr

${ }^{(10)}$ Oceanography Division, National Remote Sensing Centre, Dept. of Space, Govt. of India, Balanagar, Hyderabad-500 625, India, Email: mmali@nrsa.gov.in

${ }^{(11)}$ University of Miami, Cooperative Institute for Marine and Atmospheric Studies, 4600 Rickenbacker Causeway, Miami, FL 33149 USA, Email: Francis.Bringas@ noaa.gov

${ }^{(12)}$ NOAA (National Oceanic and Atmospheric Administration) Tropical Prediction Center, 11691 SW 17th Street Miami, Florida 33165-2149 USA, Email: Chris.Lauer@noaa.gov

${ }^{(13)}$ Florida State University, Tallahassee, 600 W. College Avenue, Tallahassee, FL 32306-2840 USA, Email: echassignet@coaps.fsu.edu

(14) Eduardo Mondlane University, Praca 25 de Junho Caixa Postal 257, Maputo 257, Mozambique, Email: amavume@gmail.com

${ }^{(15)}$ National Typhoon Center/KMA (Korea Meteorological Administration), 486-3 Topyeong-dong, Seogwipo City, Jeju, Republic of Korea, Email: krkang@kma.go.kr

\section{INTRODUCTION}

Tropical cyclones (TCs) occur in seven ocean basins: the tropical Atlantic, northeast Pacific, northwest Pacific, southwest Indian, north Indian, southeast Indian, and south Pacific (Fig.1) [1]. While sea surface temperature (SST) plays a role in the genesis of TCs, the thermal structure of the upper ocean has been shown to be an important factor for tropical cyclone intensification [2] and [3], provided that the atmospheric conditions are also favorable. The intensification of TCs includes the interaction of very complex mechanisms, such as internal TC dynamics, upper ocean interaction, and atmosphere circulation. In general, the reduction of error in the forecast of TC intensity has lagged behind that of track because of the complexity of the intensification problem, and because

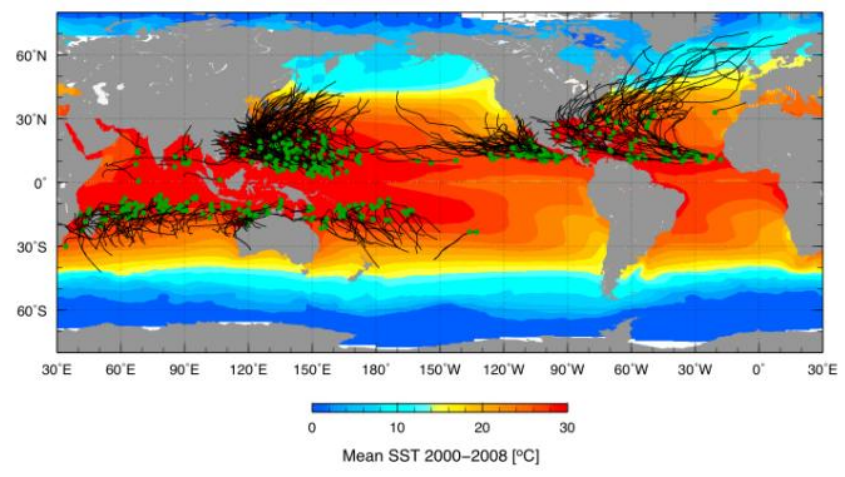

Figure1. Trajectories of tropical cyclones that reached hurricane strength (i.e., maximum sustained winds above $33 \mathrm{~m} / \mathrm{s}$ ) during 2000-2008, with green circles indicating the location where the cyclone originated, superimposed on the mean SST for the same period during the months of June-November in the northern hemisphere and November-April in the southern hemisphere 
in some cases the errors introduced in the track forecast are translated into the intensity forecast [4]. Sudden or rapid TC intensification [5] has been linked with high values of upper ocean heat content contained in mesoscale features, particularly warm ocean eddies. Therefore, resolving, understanding, and monitoring the upper ocean mesoscale field and its vertical thermal structure appear to be critical elements for TC intensification studies and forecasts.

The current ocean observing system was not designed for TC intensification or forecasting studies. In most basins, the available hydrographic and in situ observations cannot resolve mesoscale features and their vertical thermal structure with a spatial and

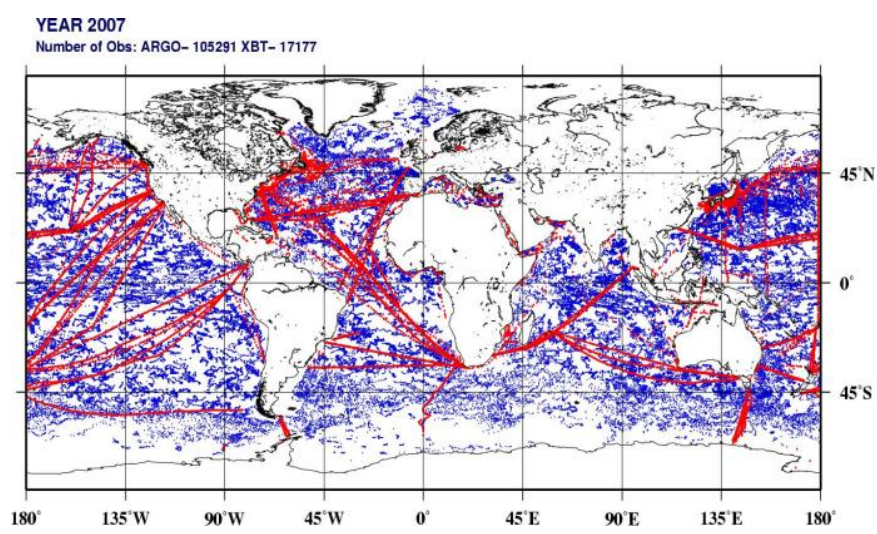

temporal resolution sufficient for TC intensification research or forecast. The present suite of vertical temperature profile observations are dominated by observations from profiling floats that are somewhat widely and unevenly spaced and by expendable BathyThermograph (XBT) transects that provide better spatial resolution but only along fixed tracks (Fig. 2, left panel). Therefore, a variety of indirect approaches and techniques are needed to estimate the upper ocean heat content. One such technique includes the use of sea surface height observations derived from satellite altimetry. These satellite-derived data provide information on the upper ocean dynamics and vertical thermal structure at a spatial and temporal resolution that resolves ocean mesoscale features.

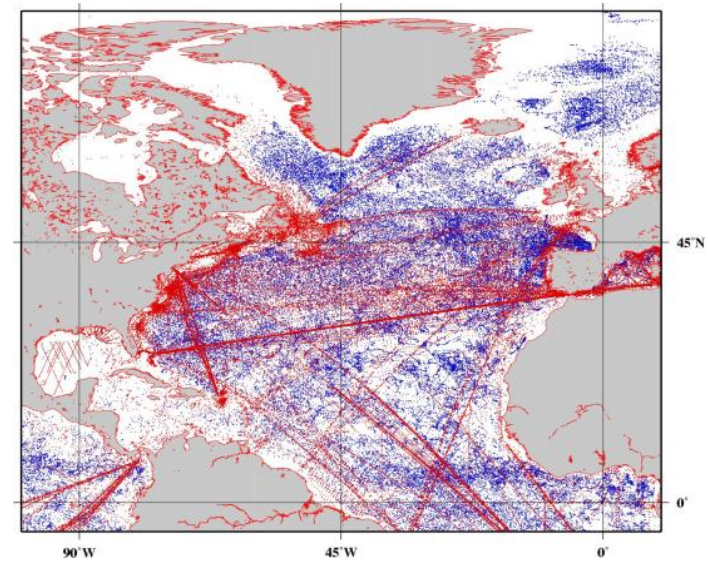

Figure 2. (left) Locations of profiling float (blue) and XBT (red) observations transmitted in real-time into the Global Telecommunication System (GTS) during 2007. (right) Locations of profiling float (blue) and XBT (red) observations in the North Atlantic transmitted into the GTS during 2003-2008.

This manuscript highlights the importance of integrated ocean data, particularly satellite derived observations and their concurrent analysis with hydrographic observations and within numerical air-sea coupled and forced ocean models. The TC intensity forecast in some basins has already incorporated upper ocean thermal information either in research or operational mode. This manuscript provides a summary of how the combination of data from several ocean observing platforms, including hydrographic, airborne, and satellite-derived observations, are being used for TC intensification studies and forecasts.

\section{NORTH ATLANTIC OCEAN}

An operational satellite altimetry-based upper ocean heat content or Tropical Cyclone Heat Potential (TCHP) analysis was implemented at the National Oceanic and Atmospheric Administration (NOAA) National Hurricane Center (NHC) in 2004 [6], following real-time tests in 2003. This approach uses sea height anomaly (SHA) fields derived from altimetry and historical hydrographic observations in a statistical analysis to determine the depth of the main thermocline, usually the $20^{\circ} \mathrm{C}$ in tropical regions [7]. Climatological relationships are then used to estimate the depth of the $26^{\circ} \mathrm{C}$ isotherm, D26 [3]. These estimated data are then used to evaluate the tropical cyclone heat potential (TCHP), which is proportional to the heat content anomaly above $26^{\circ} \mathrm{C}, \mathrm{TCHP}(\mathrm{x}, \mathrm{y})=$ cp * $\rho(\mathrm{x}, \mathrm{y}) * \int T(x, y, z) d z$, where $x$ and $y$ are the horizontal coordinates, $\mathrm{cp}$ is the heat capacity of the water, $\rho(x, y)$ is the water density, and $T(x, y, z)$ is the temperature profile.

TCHP fields are used qualitatively by the NHC forecasters for their subjective TC intensity forecasts and quantitatively in the Statistical Hurricane Intensity Prediction Scheme (SHIPS, [8]). SHIPS is an empirical, statistical model that uses multiple regression to forecast intensity changes out to $120 \mathrm{~h}$. The 2008 version of SHIPS includes 21 predictors, mostly related to atmospheric conditions. The ocean predictors are the SST and the TCHP. Despite its simplicity, the SHIPS forecasts are comparable to or more accurate than those from much more general models. For recent category 5 hurricanes, the TCHP input improved the SHIPS forecasts by about $5 \%$ (Fig. 3 , right), with larger improvements for individual storms [8]. A validation performed on 685 Atlantic SHIPS forecasts from 2004-2007 shows that the 
average improvement of SHIPS due to the inclusion of the TCHP and Geostationary Operational Environmental Satellite (GOES) infrared cloud-top temperature data reached up to $3 \%$ for the $96 \mathrm{~h}$ forecast (Fig.3, left), where nearly all of the improvements at the longer forecast intervals are due to the inclusion of TCHP. This result demonstrates that the use of TCHP generally yields improved, operational SHIPS forecasts, and especially at the longest forecast intervals and for the most intense, category 5 , storms.

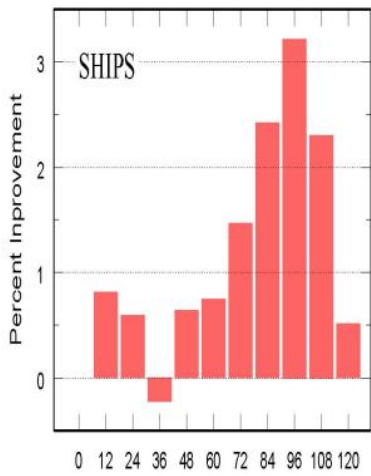

Forecast Interval [h]

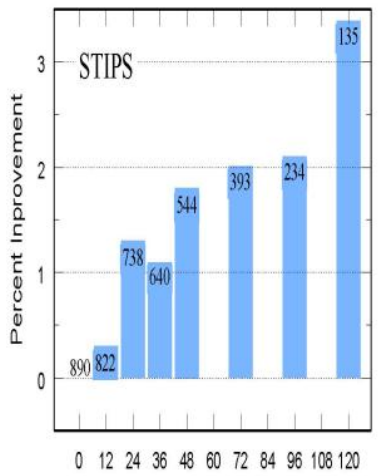

Forecast Interval [h]
Altimetry observations in conjunction with satellite SST measurements and in-situ observations are becoming important for initializing the ocean component of coupled hurricane prediction fields extracted from data-assimilative ocean nowcasts/hindcasts generated as part of the Global Ocean Data Assimilation Experiment (GODAE, www.godae.org). In particular, NOAA's Real-Time Ocean Forecast System (RTOFS) for the Atlantic Ocean is being used to initialize an experiment

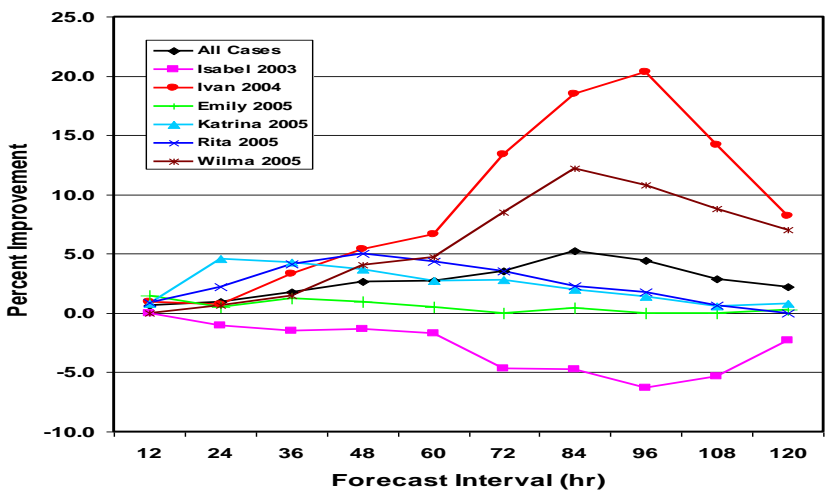

Figure 3. (left) Percent improvement of the 2004-2007 operational Statistical Hurricane Intensity Prediction Scheme (SHIPS) forecasts for the Atlantic sample of over-water cases west of $50^{\circ} \mathrm{W}$ due to the inclusion of input from TCHPderived altimetry and GOES infrared cloud-top temperature information. (center) Percent improvement that results from the use of TCHP information in the Statistical Typhoon Intensity Prediction Scheme (STIPS) forecast model. (right) The percentage of SHIPS model forecast improvement, for six category 5 Atlantic hurricanes and collectively, with the incorporation of the TCHP fields, created at the NOAA National Hurricane Center (adapted from [8]).

version of the Hurricane Weather Research and Forecast System (HWRF) by NOAA/NCEP/EMC coupled to HYbrid Coordinate Ocean Model (HYCOM) as the ocean model.

This system was tested during 2008 and is presently undergoing evaluation. The impact of ocean model initialization using GODAE ocean hindcasts was studied by using HYCOM simulations of the ocean model response to hurricane Ivan [9]. The simulation was driven by realistic atmospheric forcing generated by blending fields from the U. S. Navy COAMPS atmospheric model with higher-resolution fields from the NOAA/AOML/HRD H*WIND product [10]. The
SST response pattern due to Ivan was strongly influenced by pre-existing ocean features whose locations were accurately provided by the initialization scheme. In particular, two regions where SST cooled by several degrees Celsius were co-located with coldcore cyclonic eddies (Fig. 4), a pattern that was validated by satellite microwave SST measurements [9]. This demonstrates that mesoscale ocean features must be correctly initialized if an ocean model is to correctly forecast the magnitude and pattern of SST cooling. This capability is critically important if a coupled forecast model is to correctly predict intensity evolution [11]. 

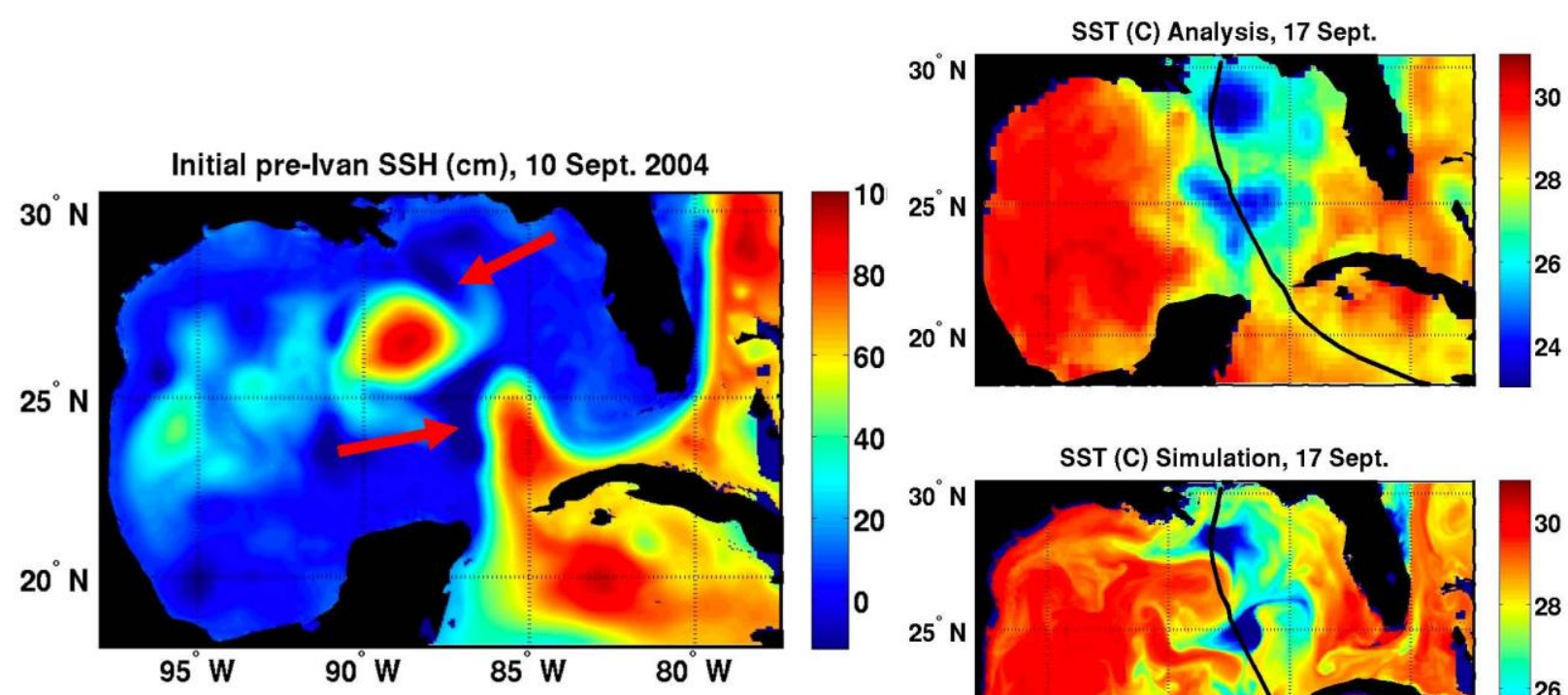

40

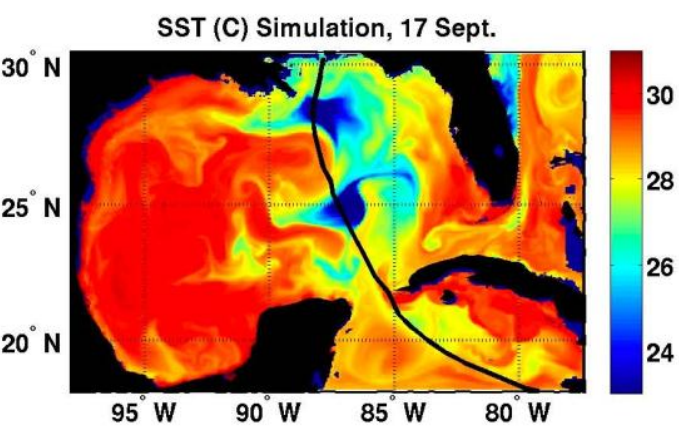

Figure 4. (left) Initial sea surface height used for the simulation of the ocean response to hurricane Ivan in the Gulf of

Mexico, with the arrows denoting the initial location of the two cyclonic eddies. (right) Two maps of sea surface temperature after Ivan made landfall, (top) one obtained using Reynolds SST analysis and (bottom) other produced by the model simulation.

A feature-based ocean initialization procedure was also created to account for spatial and temporal variability of mesoscale oceanic features in the Gulf of Mexico, including the Loop Current (LC) and eddies [12]. Using this methodology, near real-time maps of sea surface height and/or D26 derived from altimetry, are used to adjust the position of the LC and insert these eddies into the background climatological ocean temperature field prior to the passage of a hurricane. For the 2008 Atlantic hurricane season, the full version of this procedure was implemented in the NOAA Geophysical Fluid Dynamic Laboratory (GFDL) and HWRF models, which can also assimilate real-time in situ data, such as AXBT profiles. GFDL coupled hurricane-ocean model sensitivity experiments for selected hurricanes were run with and without altimeter data assimilation to evaluate the impact of assimilating mesoscale oceanic features on both the SST cooling under the storm and the subsequent intensity change of the storm. For hurricane Katrina (2005) the presence of the LC and of a warm ring, as given by the assimilated altimeter data, reduced the SST cooling along the hurricane track and allowed the storm to become more intense (Fig. 5). This assimilation improved the intensity forecast of the actual storm with respect to that obtained without assimilating the altimetry fields.

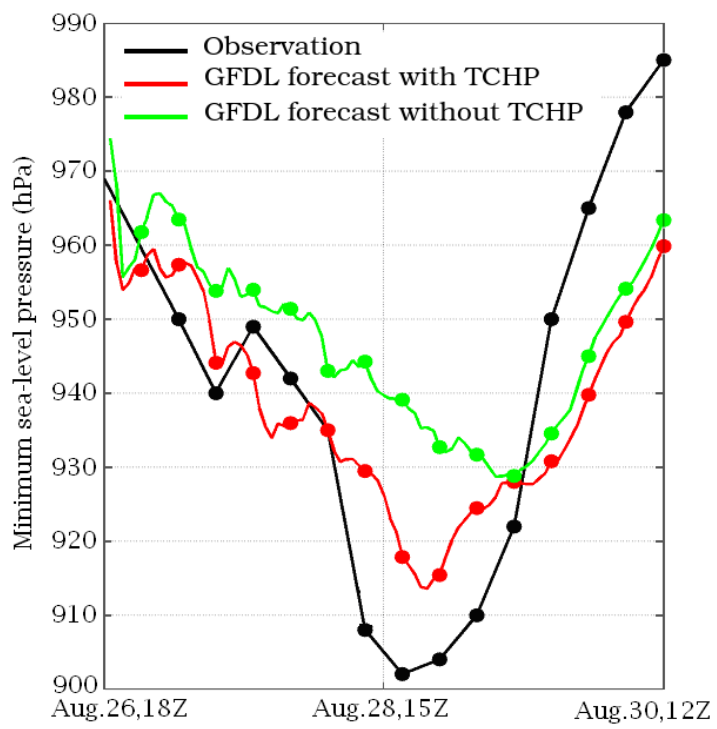

Figure 5. Minimum atmospheric pressure at sea level during the passage of hurricane Katrina in the Gulf of Mexico in 2005; showing the actual observations (black), and the reduction of error in the GFDL model output with (red) and without (green) initializing the model with the TCHP produced at NOAA National Hurricane Center. 
The altimetry-derived estimate of TCHP is analyzed when the number of available satellites is reduced on a test case corresponding to the passage of hurricane Katrina over the Gulf of Mexico (GOM).

The TCHP field in the GOM during August 25, 2005, when hurricane Katrina was located approximately on the east coast of Florida, exhibits a large anticyclonic ring in the Gulf (Fig. 6, left panel). If the TCHP field is subsampled along JASON-1 groundtrack only, the main features including the warm ring and the Loop Current still appear (Fig. 6, right panel). However, given that the groundtrack of JASON-1 does not cross the core of the ring and the jet of the LC, the values of TCHP are reduced by $30 \mathrm{~kJ} / \mathrm{cm}^{2}$ over the warm ring (Fig. 6, right panel). This is consistent with studies showing that one single satellite cannot fully resolve the mesoscale field in the ocean [13]. For instance, the 3-degree zonal distance between consecutive JASON-1 groundtracks does not allow complete identification of mesoscale features, such as warm core rings. It has been found from numerical modeling studies with the Real-Time Ocean Forecast System (RTOFS) that sea height anomaly fields from two independent altimeters are needed for adequate spatial and temporal coverage to properly position mesoscale features and fronts

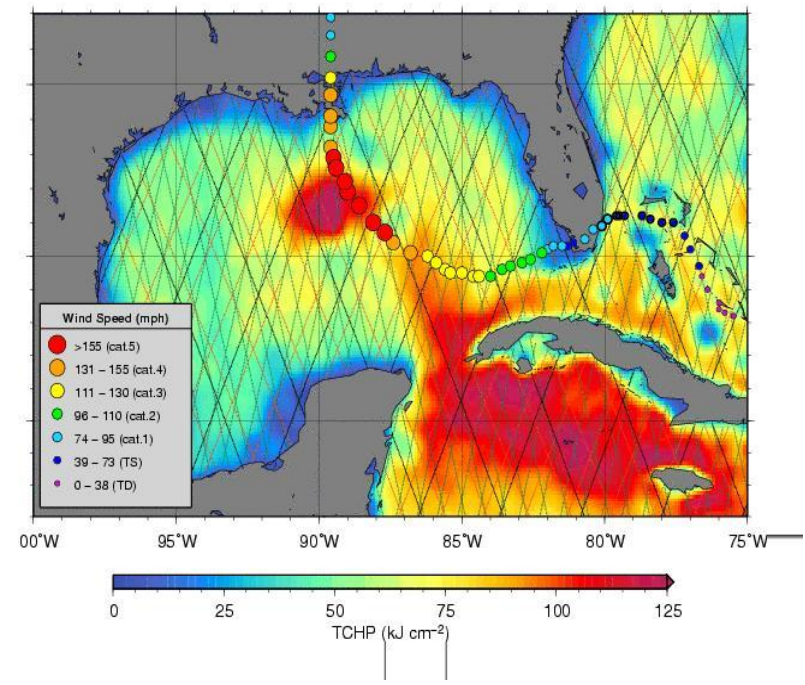

which are critical for determining impact of ocean heat content on hurricane forecasts.

Starting in 2009, the National Oceanic and Atmospheric Administration (NOAA), through the Hurricane Forecast Improvement Project (HFIP), has committed to obtaining observations of the upper ocean throughout the western Atlantic basin. More than 500 Airborne eXpendable BathyThermographs (AXBTs) will be deployed each year from NOAA P-3 aircraft before, during, and after tropical cyclone events. These observations will be used for pre-season ocean model initialization and to provide unprecedented oceanic observations on the mesoscale in and around tropical cyclones throughout the Atlantic basin for model initialization and evaluation. Additional observations from Airborne eXpendable Current Profilers (AXCPs) and Airborne eXpendable Conductivity, Temperature, and Depth (AXCTD) sensors will complement the other observations. Starting in 2009, these data will be transmitted in realtime from the NOAA aircrafts. NOAA is also cooperating with the Minerals and Mining Service (MMS), which has a series of moorings throughout the Loop Current region of the Gulf of Mexico, and the

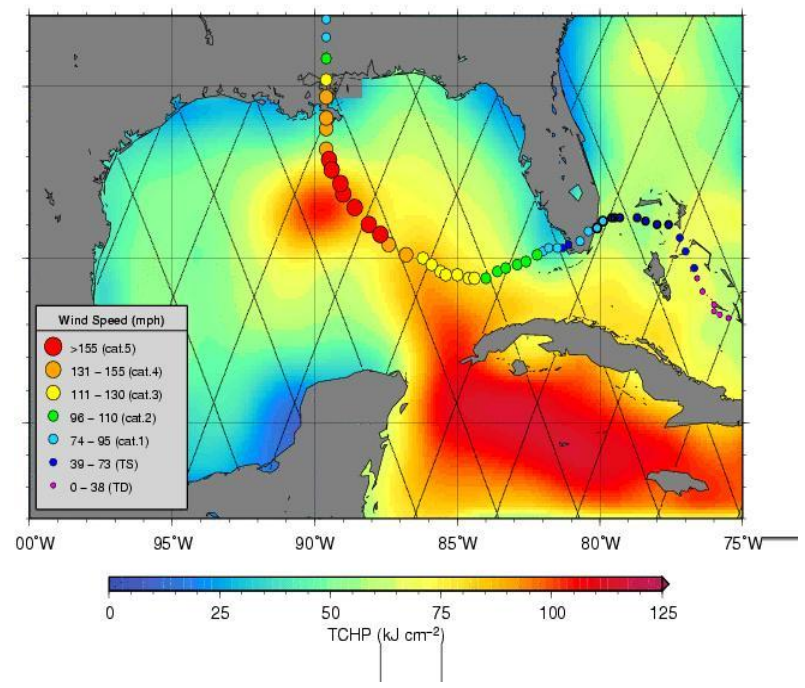

Figure 6. (left) TCHP field during Katrina obtained using data from Jason-1, GFO and Envisat. (right) TCHP field during Katrina obtained using data from JASON-1 only. The groundtracks of the satellite from which observations are used to estimate the TCHP fields are superimposed.

Mexican government, who also have a series of moorings in the Yucatan Channel and in the Loop Current.

The relative scarcity of in situ upper ocean heat content measurements in some areas of the Atlantic hurricane basin (Fig. 2) highlights the need for additional in-situ observations, for calibrating and validating altimetrybased calculations and for initializing model nowcasts and forecasts. Recent efforts to supplement the backbone observing system have focused on efficiently targeted observations ahead of major hurricanes such as Rita (2005), Dean (2007), Gustav and Ike (2008). These observations include thermistor chain drifters, measuring temperature every $10 \mathrm{~m}$ from the surface to $150 \mathrm{~m}$ depth at hourly resolution, profiling floats, and AXBTs deployed from the U.S. NOAA and Air Force aircrafts. The resulting observations have characterized 
upper ocean thermal and velocity evolution during the passage of the storms, and could be of enormous value in evaluating and improving coupled ocean-atmosphere simulations of hurricane development for improved intensity forecasting.

\section{OTHER OCEAN BASINS}

Thirty northwest Pacific typhoons that reached category 5 during 1993-2005 were examined using satellite altimetry, in situ, and climatological upper ocean thermal structure data, best track typhoon data from the U.S. Joint Typhoon Warning Center (JTWC), and an ocean mixed layer model [14]. Results indicate that the background climatological upper ocean thermal structure is an important factor in determining how warm mesoscale ocean features affected the intensification of these TCs. Two different conditions were found. The first is in the western North Pacific south eddy zone $\left(127^{\circ} \mathrm{E}-170^{\circ} \mathrm{E}, 21^{\circ} \mathrm{N}-26^{\circ} \mathrm{N}\right)$ and the Kuroshio $\left(127^{\circ} \mathrm{E}-170^{\circ} \mathrm{E}, 21^{\circ} \mathrm{N}-30^{\circ} \mathrm{N}\right)$ region, where the background climatological warm layer is relatively shallow; D26 is typically at $60 \mathrm{~m}$ depth and the TCHP is approximately $50 \mathrm{~kJ} \mathrm{~cm}^{-2}$. In these conditions, the presence (or not) of mesoscale warm features are critical for typhoon intensification to category 5. A warm mesoscale feature may cause D26 to be as deep as $100 \mathrm{~m}$, and TCHP to be as high as $\sim 110 \mathrm{~kJ} \mathrm{~cm}^{-2}$. These ocean thermal conditions restrain the typhooninduced SST cooling and hence promote intensification. In the past 13 years, 8 out of the 30 category-5 typhoons (i.e., 27\%) corresponded to this scenario. The second condition is in the central region of the subtropical gyre $\left(121^{\circ} \mathrm{E}-170^{\circ} \mathrm{E}, 10^{\circ} \mathrm{N}-21^{\circ} \mathrm{N}\right)$, where the background climatological warm layer is thick (typically D26 105-120 $\mathrm{m}$ and the TCHP $\sim 80$ $120 \mathrm{~kJ} \mathrm{~cm}^{-2}$ ). In this region, it is possible that a typhoon may intensify to category 5 when travelling above waters with cyclonic or anticyclonic mesoscale features.

Additionally, important additional research is needed in the future to perform regional validation to assess the accuracy of the satellite altimetry -derived TCHP in the various basins. A regional validation was performed to evaluate the altimetry-derived estimates of TCHP using the two-layer reduced gravity scheme described in Sect. 1 in the western North Pacific Ocean during the May-October typhoon season of 2002-2005 using more than 5000 in situ ocean depth-temperature profiles [15]. It was found that the satellite-derived estimates are applicable in the central and the southwestern North Pacific (covering $122^{\circ} \mathrm{E}-170^{\circ} \mathrm{E}$, $\left.9^{\circ} \mathrm{N}-25^{\circ} \mathrm{N}\right)$ but not in the northern region $\left(130^{\circ} \mathrm{E}-170^{\circ} \mathrm{E}\right.$, $\left.25^{\circ} \mathrm{N}-40^{\circ} \mathrm{N}\right)$. In the northern region of the western North Pacific, the two-layer based satellite-derived depths of the $20^{\circ} \mathrm{C}$ and $26^{\circ} \mathrm{C}$ isotherm were systematically overestimated, leading to an overestimation of the TCHP values. Therefore, it is important to develop, test and implement new methodologies for deriving TCHP fields in the northern part of the western North Pacific Region.

In the NW Pacific basin, a statistical-dynamical model similar to SHIPS (Sect. 1), called the Statistical Typhoon Intensity Prediction Scheme (STIPS; [16]) is being utilized. STIPS is run at the Naval Research Laboratory in Monterey and is provided to the JTWC who makes TC intensity forecasts in the western North Pacific, South Pacific, and Indian oceans. The version of the STIPS model used in the Northwest Pacific and North Indian oceans uses the global TCHP fields (www.aoml.noaa.gov/phod/cyclone) calculated along the forecast track as a predictor. This updated 13 predictor-version of the STIPS model was run in parallel for the last three years with its predecessor, which does not use the TCHP information. An independent and homogeneous sample of these parallel forecasts of 63 Northwest Pacific TCs showed that modest improvements in intensity prediction were achieved when this TCHP information was used (Fig. 3 , center). Forecast improvements achieved by using TCHP information were statistically significant in the $24 \mathrm{~h}$ to $120 \mathrm{~h}$ forecast times. Alternatives to address shortcomings in a two-layer gravity scheme for TCHP found by [15] may be partially addressed by using a full three-dimensional data assimilation, such as the Navy Coupled Ocean Data Assimilation (NCODA) [18].

The Southern Hemisphere version of STIPS [19] was recently upgraded so that it can use TCHP information. Forecasts from this version of the model were run in parallel with the previous version (i.e., not containing TCHP information). Preliminary results based on the July 2008- June 2009 Southern Hemisphere tropical cyclone season showed statistically significant improvements of roughly $5 \%$ in the TCHP-based intensity forecasts for time periods $24-48$ hours, noting that JTWCs forecasts extend through only 48 hours in the Southern Hemisphere. While this sample is relatively small and may not be entirely representative, it does show that TCHP information improves objective statistical intensity forecasting in the Southern Hemisphere.

Another study of the relationship between typhoon intensification and the ocean heat content in the northwestern Pacific Ocean was carried out by the National Typhoon Center in Korea with TCHP fields evaluated from profiling float data. Results indicated that the horizontal distribution of the TCHP values matched well the typhoon intensity change pattern, showing that the typhoons were intensified with some time lag after traveling over the regions of higher ocean heat content. The ocean heat effect to typhoon 
intensity at different time lags for each ocean heat energy level indicated that the average decrease of core pressure per 24, 48, and 72 hours under $80-100 \mathrm{kJcm}^{-2}$, were 13,26 , and $37 \mathrm{hPa}$, respectively.

The BLUElink operational Ocean Model, Analysis and Prediction System (OceanMAPS) [19] at the Australian Bureau of Meteorology (BOM) and the BLUElink ReANalysis (BRAN) [20] datasets provide the best estimate of the ocean state in the Australian region spanning from 1996 to present. Information provided by these systems is being used to estimate pre-storm TCHP fields and define the ocean state for the BOMs coupled limited area modeling and prediction system (CLAM) (Fig. 7). CLAM is a BLUElink development that consists of the BOMs tropical cyclone limited-area prediction system TCLAPS [21], a regional ocean model version of the BLUElink ocean forecasting system and the oceanatmosphere sea-ice-soil coupler OASIS3.1 [22].
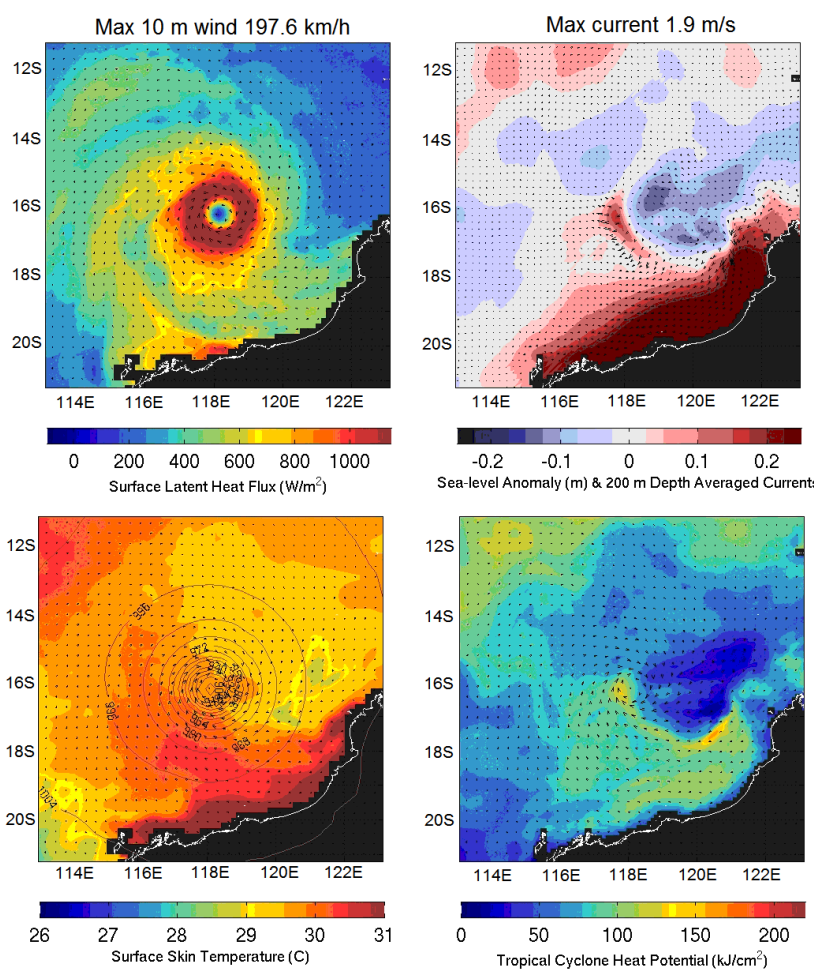

Valid date: Sun 2004-03-31 1200 UTC Forecast hr: 60

Figure 7. CLAM forecasts for Tropical Cyclone Fay using pre-storm conditions from BRAN2.1 and improvements in coupled model physics have led to improvements in TC intensity, track and ocean forecasts.

CLAM is nested inside BRAN or OceanMAPS for hindcasts/forecasts respectively. These systems assimilate data using BODAS [23] from the ocean observing system such as satellite altimetric sea-level (SLA) from JASON1, ENVISAT and GFO, sea surface temperature from AMSR-E, in situ profiles from the Argo array and XBTs from ships of opportunity in Australian regional seas. A regional version of BODAS is being implemented in CLAM and additional data streams, such as SLA from JASON2 and SST from the United States Naval Oceanographic Office's (NAVOCEANO) remotely sensed product, are being considered for defining the ocean state in the coupled tropical cyclone analysis and prediction system.

The SST, the only oceanographic input for several cyclone models in the Northern Indian Ocean does not always reflect the subsurface thermal conditions, the main driving force for the tropical cyclones. On the other hand the SHA generally reflects this parameter. The link between TC intensification and upper ocean heat content, and in particular the TCHP, has also been identified in the north Indian Ocean, showing that TCs intensify (dissipate) after travelling over anticyclonic (cyclonic) eddies. The inclusion of SHA in the visual analysis [24] has shown a good correspondence between the intensification/dissipation of the TCs and the SHA fields. In contrast, this relationship is not observed with the SST fields alone. For example, the depression that formed on May 10, 2003, intensified to a cyclonic storm as it travelled over an anticyclonic feature with a positive SHA value and it further intensified into a severe TC of 4.5 intensity, $980 \mathrm{hPa}$ central pressure and $75 \mathrm{kt}$ winds after travelling over an anticyclonic eddy with an elevation of $20 \mathrm{~cm}$ (Fig. 8a). The system weakened after travelling over a feature of SHA of approximately $0 \mathrm{~cm}$. Just before landfall, the SHA value under the track increased to 4 $\mathrm{cm}$ closer to the coast and the TC intensity increased with $994 \mathrm{hPa}$ central pressure and $45 \mathrm{kt}$ winds, revealing a close relationship between SHA values and TC intensity. In contrast, this relation is not observed between the SST and TC intensity (Fig. 8b); cyclone intensified after travelling over lower SST values $\left(30.5^{\circ} \mathrm{C}\right)$ and weakened after reaching larger SSTs $\left(31.5^{\circ} \mathrm{C}\right)$.

Additionally, the inclusion of SHA into the fifth generation National Centre for Atmospheric Research Mesoscale Model (MM5) has shown to reduce the track errors [24]. Other studies in the Indian Ocean [25], have shown the importance of the water stratification in the North Bay of Bengal, where the contribution of river runoff produces a stable warm layer at the surface. This type of condition has been hypothesized to be responsible for the intensification of Cyclone Nargis in 2008.

Recent analyses of cyclone track data in the SouthWest Indian Ocean for 1994-2007 allowed identification of 15 intense cyclones, with landfall in 
Mozambique or Madagascar. However, although there is no doubt about the general importance of high values of TCHP in the region, an assessment of these 15 TCs did not show a clear tendency for intensification over warm eddies as intensification took place also over cyclonic eddies, similar to what was found in the northwest Pacific Ocean. It is hypothesized that improved knowledge of the vertical density profile is necessary to further understand the role of the ocean in $\mathrm{TC}$ intensification in this region.

The role of the ocean on TC intensification can be investigated globally using high horizontal resolution global GODAE analyses and forecasts in near-real time (i.e. Mercator Ocean, HYCOM). These systems are
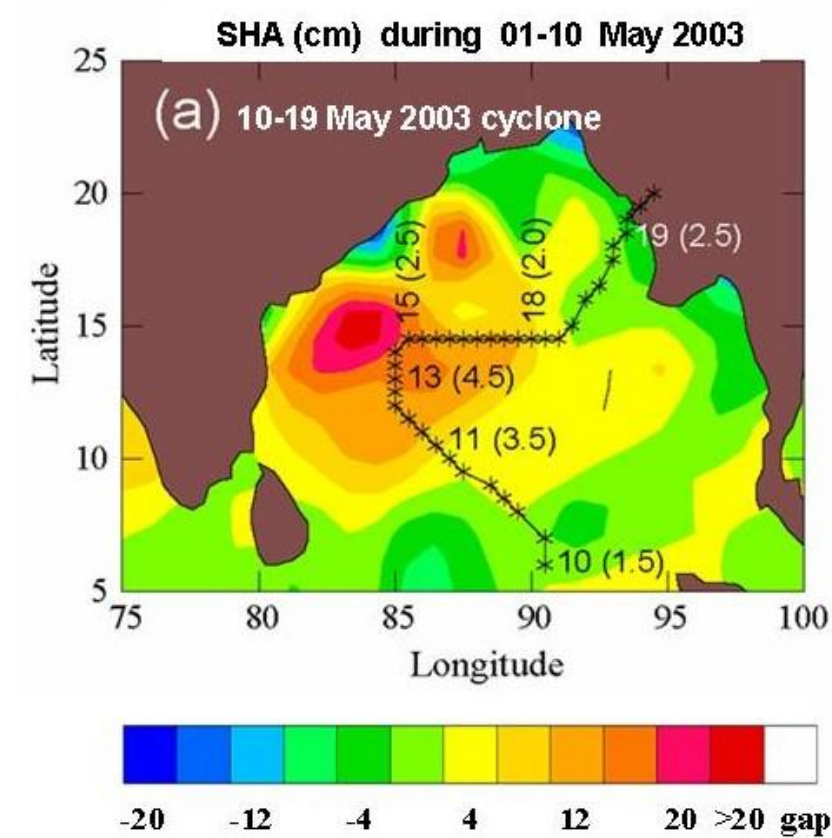

forced with atmospheric conditions supplied by ECMWF (European Centre for Medium-range Weather Forecasts), NCEP (National Centers for Environmental Prediction), or NOGAPS (Navy Operational Global Atmospheric Prediction System) and assimilate the altimeter-derived SHA fields, vertical profiles of in situ temperature and salinity (ARGO floats, XBT, CTD, and moored buoys), and SST analysis [26], [27]. Under these conditions the Mercator Ocean forecasts (MERCATOR) simulates ocean heat content interacting with the TC forecasted by the atmospheric model. In order to evaluate the MERCATOR skill to simulate daily ocean variability during TC events a point-to-point correlations between the atmospheric
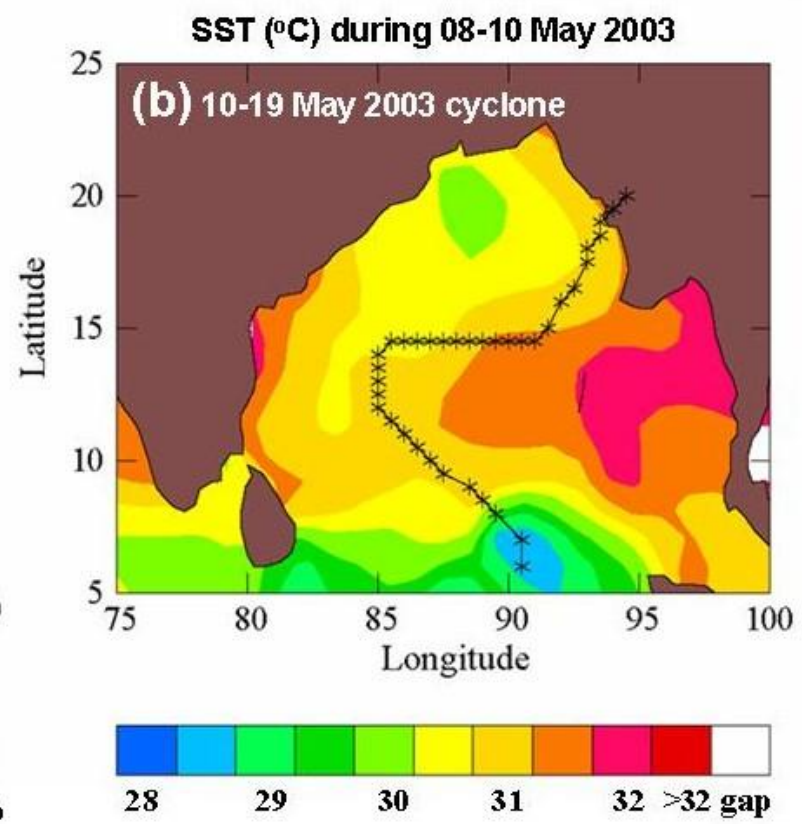

Figure 8. Impact of SHA and SST on TC intensity: (a) cyclone track of 10-19 May 2003 Bay of Bengal cyclone superimposed on the SHA field during 1-10 May 2003, (b) three day composite TMI SST during 8-10 May 2003. Time of observations (intensity) at selected locations for both the cyclones are superimposed in panel (a).

pressure $\left(\mathrm{P}_{\mathrm{a}}\right)$ predicted from satellite observations in the center of TC and the MERCATOR TCHP, SST and Mixed Layer Depth (MLD) [28] was quantified.

The delayed correlation between $\mathrm{P}_{\mathrm{a}}$ and the MERCATOR variables respectively for the days $\mathrm{J}$ and $\mathrm{J}-1$ is of the order of $15 \%$ and remains stable. Hence, a new indicator proportional to the temperature difference above $26^{\circ} \mathrm{C}$ integrated over the MERCATOR mixed layer was evaluated [29]. The delayed correlation previously defined as between $\mathrm{P}_{\mathrm{a}}$ and the MERCATOR indicator is of the order of $40 \%$. This result suggests that if the atmospheric surface forcing is realistic, the MERCATOR indicator can give the mesoscale changes in the upper ocean interacting with the TC, which then participates in the TC intensification processes. Otherwise, when the surface forcing is not realistic the MERCATOR TCHP preserves the predictability related to the lowfrequency of ocean processes. In conclusion, the mesoscale changes in the upper ocean estimated from forced ocean global models at daily scales can be used as an independent indicator (e.g. in addition to indicators from satellite altimetry or air-sea coupled models), for building cross ocean indicators and/or to improve understanding on air-sea interactions.

\section{OTHER POSSIBLE METRICS}

It is now well known and widely accepted that more than the initial (pre-TC) SST is involved in TC-ocean interaction; the subsurface temperature and in some 
cases salinity [25] are also relevant. Just exactly how ocean data should be analysed for TC-ocean interaction is still a matter of debate and ongoing research. The seminal work by [2] gave one possible prescription --the vertical integral of ocean temperature above the depth of the $26^{\circ} \mathrm{C}$ isotherm, called TCHP. High values of this metric (above $50 \mathrm{~kJ} \mathrm{~cm}^{-2}$ ) have proven very useful in identifying regions where the ocean environment is especially favorable for hurricane intensification [14]. On the other hand, low values of TCHP are not correlated with TC intensity despite that sufficiently cool SSTs have a marked damping effect upon hurricane intensity [30]. Since TCHP is zero when SSTs $<26^{\circ} \mathrm{C}$ it is reasonable to ask if there could be some other ocean metric that may be more suitable for cool ocean conditions and ideally for all ocean conditions.

Another possible metric, suggested by the dominance of vertical mixing in the upper ocean heat budget [31] is a vertical average of the upper ocean temperature [32]. The depth of vertical averaging is assumed to be $100 \mathrm{~m}$, the depth of vertical mixing caused by a mature hurricane. Of course, mixing does not go any deeper than the ocean bottom in shallow, continental shelf regions. The resulting depth-averaged temperature, T100, is an estimate of the surface mixed-layer temperature in the wake of a mature TC. High T100 indicates high SST during a TC passage, and similarly to TCHP, high T100 indicates an ocean region that is favorable for hurricane intensification.

High values of T100 can be estimated under two quite different conditions. First, where there is a thick, warm surface layer, i.e. where the SST is high and the thermocline is comparatively deep, as in the warm, anticyclones eddies of a subtropical gyre. Under these conditions, T100 is very similar to the TCHP. Second, high values of T100 are also found over shallow, warm continental shelves. A shelf water column is warm when the bottom temperature is warm, as occurs especially in downwelling favorable conditions. On the other hand, an upwelling favorable shelf may have very cold bottom waters quite close to the surface and so have very low T100. There is no lower limit built in to the cold end of the T100 domain as there is for TCHP, and so a damping effect on hurricane intensity could be within the range of $\mathrm{T} 100$. It remains to be seen from actual forecast practice [4], [6] how T100 and TCHP perform when analyzed side-by-side. And of course, there may be a third as yet undiscovered metric that outperforms either of these.

\section{FUTURE WORK AND RECOMMENDATIONS}

The current open ocean observing system was designed mainly for long time scale climate study, and not for
TC intensification studies. Although there are efforts underway to improve this system to investigate regions of TC genesis, current sustained in situ ocean observations (XBTs, Argo floats, moorings, surface drifters, etc.) do not fully support TC intensification studies. Therefore, indirect methodologies using satellite observations and numerical modeling are currently being used to monitor the upper ocean for TC intensification research. Studies performed in all ocean basins indicate that the ocean plays a significant role in TC intensification, with important details that remain to be adequately quantified. It is hoped that the ongoing work described here will stimulate studies to design an improved observing system that provides continuous observations of the upper ocean thermal structure for tropical cyclone intensification studies and forecasts. This manuscript clearly shows the need for actual observations for direct use in intensity forecast models or for ocean model validation. Future work should strive to include analysis of other upper ocean parameters besides heat content, such as the mean temperature in the mixed layer and to different depths of isotherms, including isotherms below $26^{\circ} \mathrm{C}$. Models based on statistical methodologies have shown that there is a correlation between the upper ocean thermal structure and the intensification of TCs, where mesoscale ocean features with a minimum value of

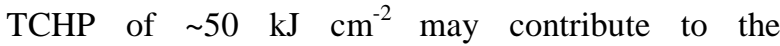
intensification of intense storms. It is clear that improved estimates of upper ocean heat content in ocean and ocean-atmospheric coupled models are critical for improvement in TC intensity forecasting. Results from some of the current efforts presented here (Tab. 1) highlight the importance of the continuous support of altimetric missions able to resolve mesoscale features.

The present effort to acquire hurricane-relevant ocean data is focused mainly on the deep open ocean, and rightly so since it is where TCs are formed and spend the majority of their life cycle. However, the study of TCs is also very important in shallow waters as they cross the continental shelf and begin to make landfall. Their last contact with the marine environment may be the most important and worthy of additional study and observation.

The utility of oceanic observations to the air-ocean interaction problem discussed here is quite evident. It is likely, however, that both our current scientific understanding and ability to improve predictions of TC intensification are both rooted in the relative scarcity of observations when compared to the atmospheric component. It is also logical that improving the density of oceanic measurements is important as more advanced oceanic modeling/data assimilation methods become reality. To make such improvements, in situ observations of the upper ocean temperature and 
salinity are needed in conjunction with more advanced and more numerous space based altimetry and passive microwave satellite. These observations would increase both the temporal and spatial quality of the upper ocean; resolving variability on inertial times and with resolutions approaching $10 \mathrm{~km}$. Specific consideration should be given to future altimeters which provide oceanic height and passive microwave sensors that have been invaluable for sensing SST changes in cloudy environments. As implied by many of the studies presented here, advanced observations should be made available in real-time (within one hour) for the data to be most useful for operational ocean and oceanatmosphere models. Such capabilities, though clearly needed, are not necessarily guaranteed given the current trends toward consolidation of future satellite and observational programs.

\begin{tabular}{|c|c|c|c|c|}
\hline Basin & Agency & Effort & $\begin{array}{c}\text { Observations } \\
\text { used }\end{array}$ & Mode \\
\hline \multirow{4}{*}{ Atlantic } & $\begin{array}{l}\text { NOAA/NWS and } \\
\text { NOAA/NESDIS }\end{array}$ & SHIPS (statistical) & $\begin{array}{l}\text { Altimetry, SST } \\
\text { Hydro clim. }\end{array}$ & Operational/Research \\
\hline & NOAA/GFDL & HYCOM + HWRF & Altimetry, SST, XBTs, Argo & Research \\
\hline & NOAA/NCEP & $\begin{array}{l}\text { POM+GFDL or } \\
\text { HWRF } \\
\text { HYCOM+HWRF }\end{array}$ & $\begin{array}{l}\text { Jason-1, Jason-2, } \\
\text { ENVISAT, AVHRR, } \\
\text { GOES, CTD's, XBT, } \\
\text { AXBT's, Argo. }\end{array}$ & $\begin{array}{l}\text { Research } \\
\text { Preparing for op. }\end{array}$ \\
\hline & Univ. Miami and NOAA & HYCOM + HWRF & Altimetry, SST & Research \\
\hline \multirow[t]{2}{*}{ NW Pacific } & Nat. Taiwan University & Ocean TCHP & $\begin{array}{l}\text { Altimetry, profiling floats, } \\
\text { XBTs }\end{array}$ & Research/analysis \\
\hline & $\begin{array}{l}\text { U.S. Navy and } \\
\text { NOAA/NESDIS }\end{array}$ & STIPS (statistical) & $\begin{array}{l}\text { NOAA/AOML TCHP } \\
\text { fields: Altimetry, SST, } \\
\text { hydro clim. }\end{array}$ & Research \\
\hline NE Pacific & $\begin{array}{l}\text { NOAA/NWS and } \\
\text { NOAA/NESDIS }\end{array}$ & $\begin{array}{l}\text { GFDL/HWRF + Point } \\
\text { model }\end{array}$ & & Operational \\
\hline \multirow[t]{2}{*}{ N Indian } & $\begin{array}{l}\text { National Remote Sensing } \\
\text { Center }\end{array}$ & $\begin{array}{l}\text { Upper ocean } \\
\text { monitoring }\end{array}$ & Altimetry & Research/analysis \\
\hline & $\begin{array}{l}\text { U.S. Navy and } \\
\text { NOAA/NESDIS }\end{array}$ & STIPS (statistical) & $\begin{array}{l}\text { NOAA/AOML TCHP } \\
\text { fields: Altimetry, SST, } \\
\text { hydro clim }\end{array}$ & Research \\
\hline \multirow{3}{*}{$\begin{array}{l}\text { SW Pacific } \\
\text { and } \\
\text { SW Indian }\end{array}$} & Australia's Bureau of & CLAM/Blue Link & \multirow[t]{2}{*}{ Altimetry, SST, XBTs, Argo } & Operational Ocean \\
\hline & Meteorology & TCLAPS & & Research/analysis \\
\hline & $\begin{array}{l}\text { U.S. Navy and } \\
\text { NOAA/NESDIS }\end{array}$ & STIPS (statistical) & $\begin{array}{l}\text { NOAA/AOML TCHP } \\
\text { fields: Altimetry, SST, } \\
\text { hydro clim. }\end{array}$ & Research \\
\hline \multirow[t]{2}{*}{ SE Indian } & University of Cape Town & Ocean TCHP & Altimetry, SST, XBTs, Argo & Research/analysis \\
\hline & $\begin{array}{l}\text { U.S. Navy and } \\
\text { NOAA/NESDIS }\end{array}$ & STIPS (statistical) & $\begin{array}{l}\text { NOAA/AOML TCHP } \\
\text { fields: Altimetry, SST, } \\
\text { hydro clim. }\end{array}$ & Research \\
\hline \multirow[t]{3}{*}{ All basins } & MERCATOR Ocean & $\begin{array}{l}\text { NEMO (Nucleus for } \\
\text { European Modelling of } \\
\text { the Ocean) }\end{array}$ & altimetry, Argo, & Operational Ocean \\
\hline & $\begin{array}{l}\text { Univ. of Miami, NOAA, } \\
\text { Florida State University }\end{array}$ & HYCOM & Altimetry, SST & Ocean/Research \\
\hline & NOAA/AOML & TCHP & $\begin{array}{l}\text { Altimetry, SST, Hydro clim, } \\
\text { Argo, XBTs. }\end{array}$ & $\begin{array}{l}\text { Ocean/Research, } \\
\text { Analysis, to } \\
\text { Operational }\end{array}$ \\
\hline
\end{tabular}

Table I. Summary of the global efforts to incorporate the upper ocean thermal structure in research and in operational mode for tropical cyclone intensification. POM: Princeton Ocean Model [33]. 


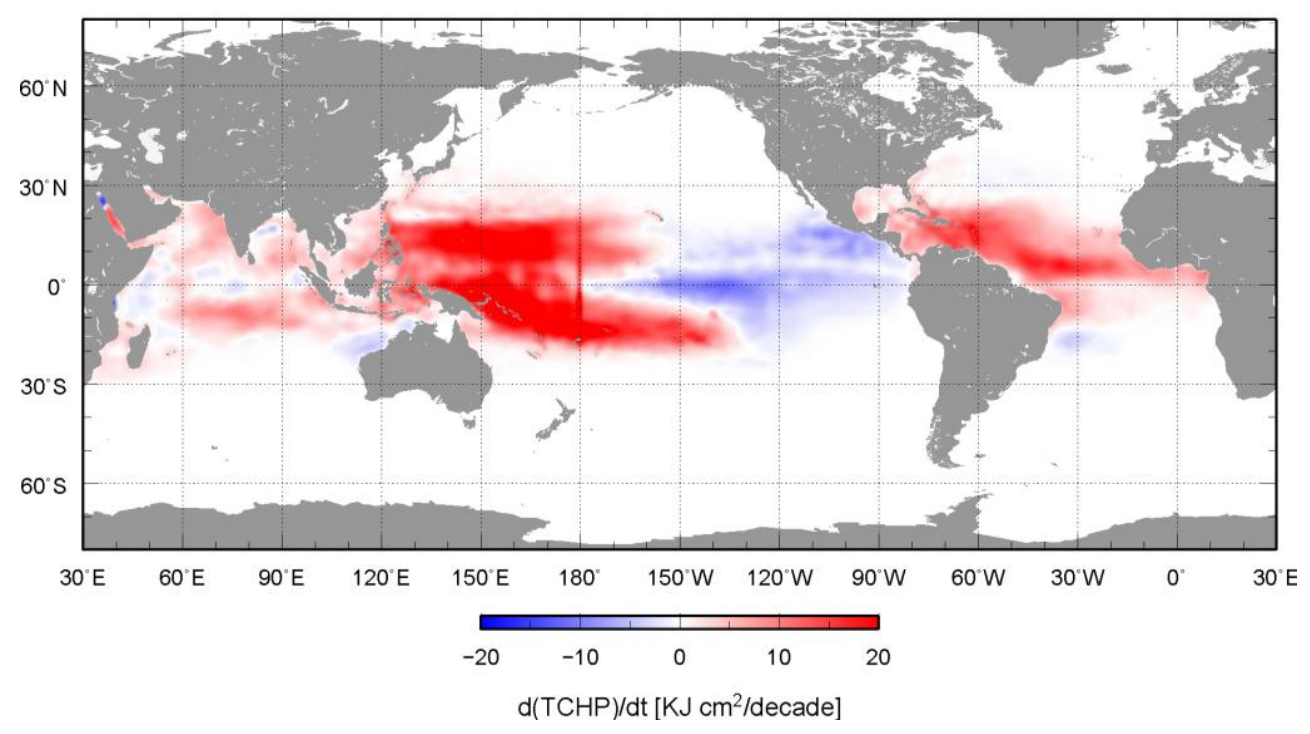

Figure 9. Global linear trends of altimeter-derived TCHP during 1993-2008.

Several research observational efforts are also underway to better understand the boundary layer of TCs and air-sea interaction. For example, one of the goals of the Intensity Forecast Experiment (IFEX) is to develop and refine technologies to improve real-time monitoring of TC intensity, structure and environment [34]. Other observational efforts have revealed the importance of the inner core SST with regards to intensification [35]. The improvement of numerical models and understanding of the role of the ocean in TC intensification will help set up the requirements for observations through the execution of an OSSE (Observations System Simulation Experiment). Improved TC monitoring will also aid in storm surge prediction, whose errors decrease if the track and intensity are of TCs are correctly forecasted.

Additionally, the investigation of interannual variability and trends of upper ocean heat content has become increasingly important for tropical cyclone genesis and monitoring [36], [37] and [1]. These trends vary regionally and their values from the 19932008 period indicate that they are mostly positive in the Indian Ocean, the western tropical and equatorial Pacific and the tropical Atlantic, while they are negative in the eastern tropical and equatorial Pacific. The highest positive trends are observed in the western Pacific with values of $40 \mathrm{~kJ} / \mathrm{cm}^{2}$ per decade, and in the tropical Atlantic with values of $22 \mathrm{~kJ} / \mathrm{cm}^{2}$ per decade. Negative trends reached values of $-12 \mathrm{~kJ} / \mathrm{cm}^{2}$ per decade in the eastern Pacific (Fig. 9). For example, the increase of TCHP values in the Gulf of Mexico could be related to a more pronounced intrusion of the Loop Current in the gulf [36] and/or to the generation of a larger number of rings. The increase in TCHP has been observed during the last ten years in most basins, and further investigation needs to be done if this trend also contributes to more occurrences of intensification.

In summary, the authors make the following recommendations:

1) Continue and support the international efforts to evaluate the role that the ocean plays in tropical cyclone intensification,

2) Support the creation and maintenance of an in-situ component of the ocean observing system, which is a complement to the current system, able to resolve mesoscale features and their upper ocean thermal structure for tropical cyclone intensification studies,

3) Support operational altimetry with a suit of satellites able to resolve mesoscale features,

4) Carry out upper ocean observations from airborne platforms, such as AXBTs and AXCTDs, before and after the passage of tropical cyclones,

5) Support new observations of other ocean parameters, such as salinity, to improve estimates of mixed layer depth properties,

6) Encourage the transmission of all observations into real-time data bases to allow immediate access to these data,

7) Support the validation efforts and improvement of ocean models that are used in TC studies,

8) Initiate an ocean Observing System Simulation Experiment, to optimize the observations made for TC studies and forecasts, and

9) Continue the strong presence of scientific presentations at international meetings and workshops. 


\section{ACKNOWLEDGEMENTS}

The work of GG, MDM, JK, CS and FB was partially supported by NOAA/NESDIS through the Research to Operations Program. NOAA/AOML also supported part of GG work. Part of CS and JK work was supported by ONR. Part of GG work was done during a rotational assignment at the NOAA/IOOS Program Office. JFP was supported by the Office of Naval Research through the project Impact of Typhoons on the Western North Pacific. Research and development of OceanMAPS and CLAM is supported by the BLUElink project, Australian Bureau of Meteorology, CSIRO and the Royal Australian Navy. The Indian National Centre for Ocean Information Services sponsored the project on North Indian Ocean tropical cyclone studies. Analysis carried out by PSV Jagadeesh and Sarika Jain in this project is gratefully acknowledged. NOAA grant NOAA4400080656, was awarded to the Graduate School of Oceanography at URI.

\section{REFERENCES}

1. Goni G. J., M. DeMaria, J. Knaff, C. Sampson, I. Ginis, F. Bringas, A. Mavume, C. Lauer, I-I Lin, M. M. Ali, Paul Sandery, S. Ramos-Buarque, K. Kang, A. Mehra, E. Chassignet, and G. Halliwell (2009). Applications of satellite-derived ocean measurements to tropical cyclone intensity forecasting. Oceanography, 22(3), 176-183.

2. Leipper, D. and D. Volgenau (1972). Hurricane heat potential in the Gulf of Mexico, J. Phys. Ocean., 2: 218-224.

3. Shay, L. K., G. J. Goni, and P. G. Black (2000). Effects of a warm oceanic feature on Hurricane Opal, Mon. Wea. Rev., 128: 1366-1383.Ali, M.M, PSV Jagadeesh and Sarika Jain (2007a). Effects of Eddies and Dynamic Topography on the Bay of Bengal Cyclone Intensity, EOS, 88: 93-95.

4. DeMaria, M., M. Mainelli, L. K. Shay, J. A. Knaff, and J. Kaplan (2005). Further improvements to the Statistical Hurricane Intensity Prediction Scheme (SHIPS), Wea Forecasting, 20: 531-543

5. Kaplan, J., M. DeMaria, J. A. Knaff, 2009: A Revised Tropical Cyclone Rapid Intensification Index for the Atlantic and East Pacific Basins, AMS, Weather and Forecasting, doi:10.1175/2009WAF2222280.1.

6. Mainelli, M., M. DeMaria, L.K. Shay and G. Goni (2008). Application of oceanic heat content estimation to operational forecasting of recent Atlantic category 5 hurricanes. Wea. Forecasting, 23: 3-16.

7. Goni, G., S. Kamholz, S. Garzoli and D. Olson (1996). Dynamics of the Brazil-Malvinas Confluence Based on
Inverted Echo Sounders and Altimetry, J. Geophys. Res., 101, 16273-16289.

8. DeMaria, M., and J. Kaplan (1994). A statistical hurricane prediction scheme (SHIPS) for the Atlantic basin, Weath. Forecasting, 9: 209-220.

9. Halliwell Jr. G. R., L.K. Shay, S. D. Jacob, O.M. Smeadstad, E. W. Uhlhorn (2008). Improving ocean model initialization for coupled tropical cyclone forecast models using GODAE nowcasts, Mon. Wea. Rev., 136: 2576-2591.

10. Powell, M. D., S. H. Houston, L. R. Amat, N. MorisseauLeroy (1998). The HRD real-time hurricane wind analysis system, J. Wind Engineer. Ind. Aerody., $77 \& 78,53-64$

11. Surgi, N. S. Gopalkrishnan, Q. Liu, R. E. Tuleya, and W. O'Connor (2006). The Hurricane WRF (HWRF): Addressing our nation's next generation hurricane forecast problems, 27th Conf. On Hurricanes and Tropical Cyclone Meteorology, CD-ROM, 7A.2.

12. Yablonsky, R. M., and I. Ginis (2008). Improving the ocean initialization of coupled hurricane-ocean models using feature-based data assimilation, Mon. Wea. Rev., 136: $2592-2607$

13. Le Traon P.Y., G. Dibarboure (1999). Mesoscale mapping capabilities from multiple altimeter missions. J. Atmos. Oceanic Technol., 16, 1208-1223.

14. Lin, I. I., C. C. Wu, and I.-F. Pun (2008). Upper ocean thermal structure and the Western North Pacific category-5 typhoons, part I: ocean features and category-5 typhoons' Mon. Wea. Rev., 136, 3288-3306.

15. Pun, I. F., I. I. Lin, C. R. Wu, D. S. Ko, and W. T. Liu (2007). Validation and application of altimetry-derived upper ocean thermal structure in the western north pacific ocean for typhoon intensity forecast, IEEE Trans. Geosci. Remote Sen., 45: 1616-1630.

16. Knaff, J.A., C.R. Sampson, M. DeMaria (2005). An operational statistical typhoon intensity prediction scheme for the Western North Pacific, Weather and Forecasting, 20: 688-699.

17. Cummings, J.A. (2005). Operational multivariate ocean data assimilation, J. R. Meteorol. Soc., 131, 3583 3604 .

18. Knaff, J.A., and C.R. Sampson (2009). Southern Hemisphere Tropical Cyclone Intensity Forecast Methods Used at the Joint Typhoon Warning Center, Part II: Statistical - Dynamical Forecasts, Australian Meteorological and Oceanographic Journal, 58: 9-18.

19. Brassington, G.B., T. Pugh, C. Spillman, E. Schulz, H. Beggs, A. Schiller and P. R. Oke (2007). BLUElink> Development of operational oceanography and servicing in Australia, Journal of Research and Practice in Information Technology, 39: 151-164. 
20. Oke, P.R., Schiller, A., Griffin, D.A. and G.B Brassington (2005). Ensemble data assimilation for an eddy-resolving ocean model of the Australian region, Quarterly Journal of the Royal Meteorological Society, $1,1-11$.

21. Davidson, N. E. and H. C. Weber (2000). The BMRC High-Resolution Tropical Cyclone Prediction System: TC-LAPS, Monthly Weather Review, 128: 1245-1265.

22. Valcke, S., A. Caubel, D. Declat and Terray, L. (2003). OASIS3 Ocean Atmosphere Sea Ice Soil User's Guide, Technical Report TR/CMGC/03-69, CERFACS, Toulouse, France.

23. Oke, P.R., Brassington, G.B., Griffin, D.A. and A. Schiller (2008). The Bluelink ocean data assimilation system (BODAS), Ocean Modelling, 21, 46-70.

24. Ali, M.M, Palash Sinha, Sarika Jain and U. C. Mohanty (2007b). Impact of Sea Surface Height Anomalies on Cyclone Track, Nature Precedings: doi:10.1038/npre.2007.1001.1.

25. McPhaden, M. (2009). Icean-Atmosphere interactions during cyclone Nargis, EOS: Trans. Am. Geophys. Union: $\quad$ 90(7); 2009; 53-60; doi:10.1029/2009EO070001.

26. Chassignet, E.P., H.E. Hurlburt, O.M. Smedstad, G.R. Halliwell, P.J. Hogan, A.J. Wallcraft, R. Baraille, and R. Bleck (2007). The HYCOM (HYbrid Coordinate Ocean Model) data assimilative system, J. Mar. Sys., $65,60-83$

27. Drévillon, M, R. Bourdallé-Badie, C. Deval, Y. Drillet, JM. Lellouche, E. Rémy, B. Tranchant, M. Benkiran, E. Greiner, S. Guinehut, N. Verbrugge, G. Garric, C-E. Testut, M. Laborie, L. Nouel, P. Bahurel, C. Bricaud, L. Crosnier, E. Dombrowsky, E. Durand, N. Ferry, F. Hernandez, O. Le Galloudec, F. Messal and L. Parent (2008). The GODAE/Mercator-Ocean global ocean forecasting system: results, applications and prospects. Journal of Operational Oceanography, 1: 51-57.

28. Ramos Buarque, S., C. Vanroyen and C. Agier (2009) Tropical Cyclone Heat Potential Revisited, MercatorOcean Quarterly Newsletter $\mathrm{N}^{\circ} 33$.

29. Vanroyen, C., C. Agier and S. Ramos Buarque (2008). Investigation on an oceanic index for monitoring Tropical Cyclones, GODAE Final Symposium, 10-15 November, Nice, France.

30. Monaldo, F. M., T. D. Sikora, S. M. Babin and R. E. Sterner (1997). Satellite imagery of sea surface temperature cooling in the wake of Hurricane Edouard (1996), Mon. Wea. Rev., 125, 2716-2721.

31. D'Asaro, E. A., T. B. Sanford, P. P. Niiler, and E. J. Terrill (2007). Cold wake of Hurricane Frances, Geophys. Res. Let., doi:10.1029/2007GRL030160.
32. Price, J. (2009). Metrics of hurricane-ocean interaction: vertically-integrated or vertically-averaged ocean temperature? Ocean Sci. Disc., 6, 909.

33. Blumberg A., and G. L. Mellor (1987) A description of a three-dimensional coastal ocean circulation model, In Three-Dimensional Coastal Ocean Models, N. S. Heaps (Ed.), 1-16, American Geophysical Union, Washington, DC.

34. Rogers, R., S. Aberson, M. Black, P. Black, J. Cione, P. Dodge, J. Dunion, J. Gamache, J. Kaplan, M. Powell, N. Shay, N. Surgi, and E. Uhlhorn (2006). The Intensity Forecasting Experiment, Bull Met. Soc. Am., 1523-1537.

35. Cione, J.J., and E. W. Uhlhorn (2003). Sea surface temperature variability in hurricanes: Implications with respect to intensity change. Mon. Wea. Rev., 131: 17831796.

36. Goni, G. J. (2008). Tropical Cyclone Heat Potential, in State of the Climate in 2007, Bull. Am. Met. Soc., D.H Levinson and J.H. Lawrimore (eds), 89: 43-45.

37. Goni G. J. and J. Knaff (2009) Tropical Cyclone Heat Potential, In State of the Climate in 2008, 90, S54-S56, Bulletin American Meteorological Soc. 